\title{
Evviva La Musica: The Music of Language
}

\author{
Grace Elizabeth Diane Bone \\ Our Lady of the Way Primary School, Brisbane, Australia
}

\begin{abstract}
Three years ago, I applied for and was successful in receiving a grant from Brisbane Catholic Education. This was for an action project to investigate how Information Communication and Learning Technology (ICLT) resources could enhance language learning. From my first project, reflecting on student responses to my questionnaires, many indicated that they enjoyed learning Italian through music or songs. The focus for my second language grant, "learning Italian grammar through songs", evolved from reflecting on my student responses on their learning and listening to student voice. From my observations of student engagement and again consulting students' ideas, it was evident that the students' enjoyment of the learning experiences was the driving factor which engaged them in their learning. Analysis of the quantitative data taken from a grammatical pre-test and post-test, revealed that the frequency of listening to and singing the songs influenced the students' recall, understanding and being able to identify the grammatical terms for specific words, in particular, the songs that the students had been learning for many years, even from Prep, Years one and two. For my next project, I shall be investigating "having an ear for languages" and "having an ear for music" and how the two correlate.
\end{abstract}

Keywords: listening, learning, language, music

Language is the instrument.

-Year six student

OLW School

\section{Introduction}

I teach Italian and music at a primary school in Brisbane. Since 2012, I have been researching how students learn another language other than English. I have conducted three consecutive action research projects in the Italian classes. The first project investigated how the use of technological resources could enhance the teaching and learning of Italian. The following two projects evolved from acting on student feedback. These investigations have led to the discovery that students' engagement with music enhances their love of and competency in language learning.

Music moves the soul. Imagine foreign languages are like keys, both in the musical and physical sense. The more keys your voice can produce equal the more physical keys you have to open doors to new horizons (Zaraysky, 2009, p. 13). Language is a window to the world (Zaraysky, 2009, p. 17).

\section{Music and Cultural Celebrations at Our Lady of the Way school: "Il Carnevale"}

To give the students the opportunity to engage in the Italian culture, I introduced Carnevale Day

Grace Elizabeth Diane Bone, Italian language and music teacher, bachelor, Languages and Music, Our Lady of the Way Primary School. 
Celebrations to the school. From 2007 to 2011, we have had costume parades with students wearing the masks that they created, cooking activities, storytelling by grandparents (Nonno and Nonna), and students making Pinocchio puppets. Students in each year level learnt songs in Italian, traditional Italian dances and performed these for the whole school.

In 2008, I was asked to give a presentation for language teachers in the Brisbane Diocese at an annual in-service to share the success of musical and cultural activities of our Carnevale program.

\section{Teaching and Learning Italian at Our Lady of the Way Primary School: The School Context}

Having been at the same school for 15 years and teaching Italian since 2006, I have worked collaboratively with four principals during that time. All four principals have been keen to foster languages learning within the school. Being a long serving classroom teacher, perceptions of language teaching have been more positive. Teaching in a classroom role as well as teaching Italian provides me with insight that I understand what is happening across the curriculum and school community.

The perception of how languages are received in the school is based on my surveys of teachers, students, holding information nights, submitting articles for the school newsletter and conversations with the leadership team.

\section{Enhancing the Profile of Learning Languages in Primary Schools}

My journey of teaching language, integrated with music has been supported by Brisbane Catholic Education. I have been given opportunities to share my story about improving language learning through music. These include: preparing and delivering a presentation in 2011 to language teachers at an annual in-service as well as delivering two presentations focused on sharing the results of my research projects. In July 2015, I shared my research results in a poster presentation at the AFMLTA Conference in Melbourne.

\section{Inspiration to Conduct Action Research Projects in the Italian Language Classroom}

Since 2011, Brisbane Catholic Education has offered grants to language teachers to implement Action Research Projects to enhance their teaching of languages and study the changes in student learning. The first round of projects aimed to investigate how the use of Information Communication Learning Technologies impacts on the students learning languages. At the annual "Languages Expo", held here in Brisbane, teachers of other languages share their documented results. Attending these professional development days inspired me to consider applying for such a grant for our school.

Since the initial focus from the grant was on the introduction of ICLT resources in the languages classroom, I submitted my application for a grant focusing on digital learners.

The title for my first project was "An Iclt Approach to Italian Language, Culture and Learning-Attività Realistiche".

My project focus was improving Italian proficiency and engagement through the introduction of technologies: mobile (iPads), lap tops, interactive whiteboard in alignment with the Australian Curriculum.

My first open-ended question for investigation was: How does the use of technology impact on student engagement in language lessons and increase their proficiency in Italian language and culture? 


\section{Using ICLT Resources When Singing in the Italian Language Classroom}

One of our school's pedagogy is for students to aim for $100 \%$ in their work and habits. Students demonstrated a keen interest in recording their singing using the Sock Puppet App which they then replayed their recordings using the interactive whiteboard for the teacher and the class to evaluate their fluency, expression, and pronunciation. "From a digital perspective: digital learners prefer to network simultaneously with many others. Digital learners prefer processing pictures, sounds, colour and video before text. Digital learners prefer instant gratification and immediate rewards" (Jukes, McCain, \& Crockett, 2010, p. 42).

\section{Development of Three Action Research Projects, Two of Which Evolved From Students' Feedback}

Considering the quantitative and qualitative data from my first project (cycle 2012-2013), I listened to "student voice" and reflected on their responses from my questionnaire, e.g., what is that you like learning about Italian? Some of their responses included these suggestions. "I like singing and talking in Italian"; "We have lots of fun in our lessons"; "I like the music and movement in the songs" (personal communication).

The majority of the positive responses mentioned songs and music. A lot of students during the implementation of the second language research project would spontaneously dance to the songs while others created percussion rhythms to accompany the songs. The success of this project led me to develop my second language project, which aimed to further investigate why the students were so keen to learn Italian through singing and music.

\section{Visible Learning-Student Voice}

As McIntyre, Pedder, and Rudduck (2005) in John Hattie's Visible Learning for Teachers (2012) noted:

It is as easy as it is legitimate for teachers to claim that students' suggestions rarely take adequate account of the complexity of the teacher's task, but it is only those teachers who have the mind frame that students' perceptions are important who make the sustained efforts needed to engage students more in learning. (p. 38)

The Action Plan title for my second project was "Learning Language Through Music".

The Action Plan focus was learning, understanding, and applying grammatical skills to enhance students' proficiency in speaking, reading, and writing in Italian through listening to and singing songs in Italian.

The title and focus for my second grant evolved from the students. A Year five student commented that: "Learning a language through songs makes it fun and enjoyable" (personal communication). From my observations, it was evident that the students' enjoyment was the driving factor which engaged them.

My second question for investigation was: How do the elements of music (songs, lyrics, jingles, rhythm, rhyme, melody, and repetition) influence learning of Italian?

\section{Implementation of My Second Action Research Project Using Music as a Vehicle for Teaching and Learning Languages}

\section{Learning Intentions}

We can learn to use key grammatical knowledge and structures to form sentences and text to show understanding and to convey meaning by listening to and singing songs in Italian.

When writing learning intentions: "It's important that students know where they are going in their learning and what it looks like to be successful" (William, 2011, p. 69). 


\section{Success Criteria}

Students will be able to:

(1) Understand the main points in spoken texts containing familiar language in simple sentences;

(2) Understand short written texts with varied sentence structures and some unfamiliar vocabulary;

(3) Create short texts on a range of familiar topics, expressing meaning in simple sentences through the use of present tense of verbs, nouns, adjective;

(4) Discern patterns and features of the Italian written language and compare them with English. ${ }^{1}$

\section{Analysis of the Qualitative and Quantitative Data}

As part of my data collection for my second project, students in Years four, five, and six were asked to complete a questionnaire about language and music.

Students were asked to interpret this statement: "language is music" and write their thoughts about their understanding. The majority of the students responded with the musicality of language as their focus.

Fluent language is a lot like a song. Music is a way to learn languages. Music is another way of communicating in languages. Some people find it easier to understand emotions and language through music. When you listen to the music, the words become clearer. When you speak, your voice sort of flows, like when you are singing. Language is like music because it goes up and down when you are speaking. Songs or music tells a story and then you can sing it. I think Italian is musical because it has its own rhythm. Language is like a rhythm which runs like liquid, smooth and calm. When you learn a new language, it's like learning a new instrument. (personal communication)

\section{Learning Language Through Music: Music Is Integral in Communicating}

Learning a new language means you have to change your key and tune. Dancing the cha-cha to waltz music is like speaking a new language while still using the rhythm of your mother tongue. Let yourself take in the sounds of the language as though you were listening to a piece of music. (Zaraysky, 2009, p. 28)

Students were then asked to consider how learning the lyrics of songs in Italian would help them learn Italian. The majority of the students' responses indicated that it was their enjoyment of singing the songs that assisted them in their learning. It was evident that the students' enjoyment was the driving factor for engaging them.

Learning a language through songs makes it fun and enjoyable. The words are catchy and they will get stuck in my brain and it's easier to learn the words. It's a lot of fun and music has good rhythm and it will be easier for me to remember. I can understand more of the Italian culture. You become familiar with the words because you like singing the songs. (personal communication)

Since my second language project was to investigate if learning songs would improve the students' grammar, the next question was to ask what the students understood about grammar. The majority of the students responded with the understanding that grammar is the verbs, adjectives, nouns, etc., that you use to make sentences with.

When researching the link between language and music, I received an email from Language Tech News. Susanna Zaraysky has posted her insights about learning many languages through music from her book Language Is Music. In this text, Susanna shares the joint passion of teaching grammar through songs and music.

${ }^{1}$ ACARA: Australian Curriculum: Languages: Italian—Foundation to Year 10. 
In Susanna Zaraysky's story: While reading Dr Oliver Sack's book Musicophilia, about the neurological aspects of music, Susanna was inspired to write about how music helped her learn 10 foreign languages.

Grammar is like a mathematical formula to learn and apply when learning languages. You still have to learn grammar to know the structure of the language you are learning. Just like musicians have to know chords, timing and other music fundamentals, you need the same for languages. (Zaraysky, 2009, p. 19)

For my next question, students were asked to share their thoughts on what they understood about this statement: "Grammar is like a mathematical formula".

Students connected grammar with being the foundation for creating sentences for writing.

It's like a science project. You need a recipe/formula to complete. You can explain these signals like in Maths. Like Maths without numbers, but words. It's what makes writing a whole. Grammar is like a combination. If you know the rules, you can understand the sentences. It's like a logical explanation of the way words are formed. (personal communication)

To complete the questionnaire, the students were asked to consider how learning songs would help them understand the grammatical features of Italian. The majority of students thought it would help them retain the rhythmic patterns of language

Because it's fun to sing songs so I think I will enjoy the learning. It will help you remember the words. It will help by having a tune pattern in my head. Practise, practise; that's the way to learn. Music is like mathematical thinking. If you practise a lot, you will get a picture in your head and then you'll learn and remember. It will help me understand how the words change using the grammar rules. Going along with the musical rhythm, it will help you write sentences in Italian. Language is like a rhythm which runs like liquid, smooth and calm. When you speak, your voice sort of flows, like when you are singing. I think Italian is musical because it has a rhythm all of its own. (personal communication)

Analysis of the grammatical pre-tests and post-tests revealed that the frequency of listening to and singing songs influenced the students' recall and understanding, in particular, those songs from Prep, Year one and two. The results for the pre-test of grammar identification and comprehension were $84 \%$ and post-test were $93 \%$ as compared with the results of pre-test was $68 \%$ and post-test was $75 \%$. These were from the songs that the children had learnt during one year. The results revealed that repetition of the songs was the key element in understanding the grammar. "Music is a language, learnt in the same way we learn any language - immersion, repetition, and exchange- until we eventually reach the point of independent expression" (Lloyd, 2014, p. 39).

Analysis of comprehension tests revealed that students' comprehension of words, phrases, and sentences from songs that they had been learning for many years, i.e., from the beginning of their educational journey at Primary School, showed an increase from $84 \%$ to $93 \%$. Comparing this result to that of the students' comprehension of words, phrases, and sentences from songs that they had been learning in one year at school, the results revealed an increase from $68 \%$ to $75 \%$. Perhaps this can be related to the quote from Paula Coelho.

"Routine has nothing to do with repetition. To become really good at anything, you have to practice and repeat, practice and repeat, until the technique becomes intuitive".2.

\section{Conclusions Drawn From My Second Project}

From observations and anecdotal records in my reflective journal, I noted that students were more successful in identifying the grammatical features of text in the songs because of the familiarity and repetition of the words which promoted understanding and recall. Music gets the whole child involved in the process of learning.

\footnotetext{
${ }^{2}$ See izquotes.com.
} 
Students are always keen to sing a variety of songs in Italian. Each week, the students would request more songs to learn. Many students created rhythmic patterns, using rhythmic sticks, to accompany the melodies. Student motivation and participation in performing the songs for their peers in class time was enhanced as well as singing songs in Italian for these Whole School Liturgies: Mother's Day_-"Mamma" and Our Lady of the Way Patron's Day: “Ave Maria".

Music is naturally repetitive. Nearly every song has a chorus written into it, and this repetition aids our memory. When students are repeatedly exposed to the same language over a period of time, it transfers to our long-term memory and we can recall it days, weeks or even months later; i.e., vocabulary, phrases, and entire sentences (from five Reasons Music is a great learning resource).

\section{Feedback and Consultation With the Wider School Community}

As part of my research, teachers were asked to give their perspectives on how music could help teaching and learning languages. The responses focused on the musicality and rhythm of language.

Language has a rhythm and beauty to it. Music is catchy and usually repetitive, fun for the children to learn. Music is integral in learning to communicate in languages. Language has patterns that speak to the heart. Repetition, rhythm and rhyme build phonemic awareness. Much of language is beyond words. Music brings that extra layer. ${ }^{3}$

Reflecting on the results of the 2013-2014 cycle of action research, defined the direction for my next project for 2014-2015. This evolved from listening to student voice. Feedback from questionnaires highlighted their interest and learning languages through music.

\section{The Action Plan Title for My Current Research Project Is: "Evviva La Musica"}

The Action Plan focus is: "Language and culture are integral to language learning and use. The intention is for students to engage with imaginative experience by participating in, responding to and creating a range of imaginative texts such as songs and music" (ACARA—communicating strand-responding to and expressing imaginative experience).

My third question for investigation: How will learning to play traditional Italian instruments to accompany songs (in Italian) influence and impact on understanding of Italian and culture?

In implementing my next action research project, the student will have the opportunity to play traditional Italian instruments (mandolins and guitars) while singing. I ask the students for more specific information: What is it about the songs and music that you enjoy and why does it help you learn? Is it the engaging rhythm? Does it make you feel like dancing? Is it the catchy melodies that make you want to sing? Is it the repetitive lyrics that help you remember?

Lesley Harbon mentions having "an 'ear' for languages" in her address at the AFMLTA 19th biennial conference, Canberra, Australia, 2013. Harbon in her article in the Babel Journal suggests that:

"The phrase 'to have an ear for languages' is usually associated with having an ear for music or poetry or languages and refers to a person being good at hearing, repeating and understanding sounds" (Harbon, 2014, p. 14).

According to Plato,

Music is what penetrates from deeply into the recesses of the soul. George Tsoulas (2014) states that there are further questions to ask about the relationship between music and language, such as whether musical education influences our way

3 Teachers' reflections. 
with language. Learners with a musical background were found to be better at pronouncing the sounds of a second language and at perceiving the relevant contrasts between sounds in a new language. (Harbon, 2014, p. 14)

With the introduction of musical instruments to our school, our Principal asked me to take on the role of music and language teacher, thus providing me with the opportunity of integrating these two subjects.

\section{DATA Collected to Date}

$84 \%$ of high achievers in learning Italian in the whole school profile are also competent musicians who take private lessons in piano, guitar, and violin and are vocalists who sing in the school choir.

In Year four, eight out of the nine high achievers in Italian also take private lessons in learning to play a musical instrument, i.e., guitar or violin. The student without experiencing lessons to learn to play a musical instrument speaks a second language, Spanish.

In Years five and six, 12 out of the 13 high achievers in Italian also take lessons to play these instruments, i.e., guitar and violin. The other student has an environmental language background and a rich family musical influence.

\section{Observations}

Students in Years four to six who are currently learning to play the mandolin and guitar in music lessons at school are experiencing success because they can see the patterns in the music and enjoy the repetition of learning the melodies.

Students in Years four to six are showing enthusiasm for learning to play the mandolin and guitar as well as an increased level of interest in learning Italian. They understand and value the practice of repetition: "La ripetizione è la madredellamemoria".

\section{Conclusion}

When I commenced teaching Italian I provided cultural experiences for the students to engage in language learning through music. Italian is very much part of the school's context with visible learning. A series of action research projects saw the integration of ICLT resources, music, and language learning. Student voice provided strong evidence of the link between music and language learning. Analysis of pre and post tests revealed that learning a language through music influenced students' recall and understanding of grammar, showing a definite improvement in their results. The evidence clearly indicates that music is the medium through which students experience success in language learning. My current research continues to investigate the link between learning a language and music where language is the instrument.

\section{References}

Harbon, L. (2014). AFMLTA 19th biennial conference Horwood Address: Accomplished teaching of languages and cultures doesn't happen by chance: Reflective journal entries of a "returnee" to the learner seat. BABEL, 49(1).

Hattie, J. (2012). Visible learning for teachers: Maximizing impact on learning. New York: Routledge.

Tsoulas, G. (2014). Explainer: How are learning languages and music linked? Retrieved from $\mathrm{http}: / /$ theconversation.com/explainer-how-are-learning-languaes-and-music-linked-34325

Jukes, I., McCain, T., \& Crockett, L. (2010). Understanding the digital generation-Teaching and learning in the new digital landscape. Kelowna, Canada: 21st Century Fluency Project, \& Corwin: A Sage Company.

Lloyd, K. (2014). Discover the music within-how and where do I begin? Education Young Children: Learning and Teaching in the Early Childhood Years, 20(3), 38-40. 
William, D. (2011) Embedded formative assessment. Bloomington, IN: Solution Tree.

Zaraysky, S. (2009). Language is music. Cupertino: Create your world Book Series. 